\title{
Comensalidade e cuidado: \\ meninas-jovens-mulheres órfãs no contexto de HIV/Aids
}

Sueli Aparecida Moreira ${ }^{1}$

Ivan França Júnior ${ }^{2}$

José Ricardo Ayres ${ }^{3}$

Michelle Medeiros ${ }^{4}$

MOREIRA, S.A. et al. Commensality and care: orphan girls and young women in the context of HIV/Aids. Interface - Comunic., Saude, Educ., v.16, n.42, p.651-64, jul./set. 2012.

"Monopoly of the kitchen" is historically and culturally attributed to women and mothers. To care for their families, they select and buy food, and cook and serve it. They sustain commensality. In contexts of HIV/AIDS, when mothers die, the daughters become responsible for such care. What do the girls think of the caregiver's role that they prematurely have to face? What do their brothers think about this? Semi-structured interviews were conducted with 14 young orphans. The data were analyzed as proposed by Mills (2009). The young women did not show any dissatisfaction with the new tasks that they were doing, but deplored the fact that this impeded them from studying and having a life beyond the home. Their brothers viewed dealing with the kitchen as women's business and rarely collaborated. These young women need care directed towards the vulnerable situation in which they live. Public health policies could seek macrostructures that would act on this demand.

Keywords: Commensality. Care. Orphanhood. Aids. Young people.
O "monopólio da cozinha", histórica e culturalmente, é atribuído às mulheres, mães. Para cuidar da família, elas elegem alimentos, compram, cozinham e os servem. Sustentam a comensalidade. Em contextos de HIV/Aids, onde há perda da mãe, as filhas tornam-se responsáveis por esses cuidados. O que pensam as meninas do papel de cuidadoras com o qual, prematuramente, deparam-se? 0 que dizem seus irmãos sobre isso? Realizamos entrevistas semidirigidas com 14 jovens órfãos. Os dados foram analisados pela proposta de Mills (2009). As jovens não demonstram insatisfação por executarem novas tarefas, mas deploram o fato de impedirem o estudo e a vida além-casa. Seus irmãos entendem a lida da cozinha como coisa de mulher e, por isso, dificilmente colaboram. Essas jovens necessitam de cuidados direcionados à situação vulnerável em que vivem. As políticas de Saúde Pública poderiam pleitear macroestruturas que atuassem sobre essa demanda.

Palavras-chave: Comensalidade. Cuidado. Crianças órfãs. Síndrome da Imunodeficiência Adquirida. Jovens.
* Elaborado com base em Moreira (2009); projeto parcialmente financiado pela Fundação de Amparo à Pesquisa do Estado de São Paulo (Fapesp) e aprovado pelo Comitê de Ética em Pesquisa, da Faculdade de Saúde Pública da Universidade de São Paulo (FSPUSP). A autora, bolsista de doutorado do CNPq, foi contemplada com o Prêmio SantanderBanespa de 2007.

1 Departamento de Turismo, Centro de Ciências Sociais

Aplicadas, Universidade Federal do Rio Grande do Norte (UFRN). Av. Sen. Salgado Filho, 3000, Lagoa Nova. Natal, RN, Brasil. 59.072-970.

suelimoreira@ufrnet.br

2 Departamento de Saúde Materno-Infantil, Faculdade de Saúde Pública, Universidade de São Paulo (USP).

${ }^{3}$ Departamento de Medicina Preventiva, Faculdade de Medicina

${ }^{4}$ Pós-graduanda Programa de Ciências Sociais, UFRN 
Meu lado mulher esforça-se por livrar-se do modelo emancipatório que adota, como paradigma, meu lado homem. Serei ela se ousar não querer ser como ele. Sereia em mares nunca dantes navegados, rumo ao continente feminino, onde as relações de gênero serão de alteridade, porque o diferente não se fará divergente. Aquilo que é, só alcançará plenitude em interação com o seu contrário. Como ocorre em todo verdadeiro amor.

(Betto, 2011, p.1)

\section{Introdução}

Este não é um ensaio acadêmico, tão pouco é um estudo ontológico ou genealógico do cuidado. Não é de nosso interesse fazer uma explanação sobre o cuidado, explorar a fábula de Higino, apresentar uma síntese do pensamento ontológico de Heidegger sobre o cuidado ou reconstruir uma genealogia à moda de Foucault sobre o cuidado de si (Boff, 2008; Ayres, 2004). Isso já foi feito. Usaremos, sem dúvida, o trabalho dessas grandes constelações de pensadores como pistas cognitivas, já que falar em humano implica falar em cuidado.

Este, também, não constitui um trabalho de gênero que pretende alimentar a antiga guerra dos sexos. Masculino e feminino, como animus e anima, são oposições binárias presentes em cada um de nós, homens ou mulheres. Ainda que homem ou mulher sejam simplesmente seres humanos e, por isso, compartilhem da universalidade da cultura, numa hibridação integral entre natureza e cultura, as mulheres foram feitas e se fizeram geradoras de vida, metáforas do alimento, ícones do cuidado.

Sobre o que falaremos, então? Esse é um trabalho sobre a comensalidade. Sobre o conviver à mesa. Sobre companheirismo, comer o mesmo pão, alimentarse juntos, comer da mesma panela. "Manger à la même écuelle, é confiança, irmandade, fusão", nos ensinou Cascudo (2004, p.42). A comensalidade, ou rito de beber e comer em conjunto, é um rito de agregação, um sacramento de comunhão (Van Gennep, 1977). O símbolo da partilha é grandemente significativo, constituindo-se a comensalidade uma das expressões da solidariedade básica do grupo familiar. É na partilha que se funda a família 5 . É sobre esse rito de união que versa este ensaio.

A figura feminina surge engrandecida nesse contexto, visto sua posição de promotora de momentos de partilha. A lida nos bastidores, a responsabilidade pela cozinha, o espaço do culinário - que, para Lévi-Strauss (2004), constitui o espaço no sentido social que dá conta da divisão sexual do trabalho e das relações estruturais nas famílias - sempre estiveram a cargo de mulheres. Contudo, as questões que tratam de homens e mulheres são construídas na sociedade em uma interação dinâmica de informações entre natureza e cultura. Mesmo diante do legado de cuidar, as mulheres nem sempre estiveram em desvantagens em relação aos homens.

A desigualdade de gênero existe apenas há cerca de seis mil anos, e deriva, não de características biológicas inerentes a homens e mulheres, mas de circunstâncias histórico-sociais. Três processos sócio-históricos dão conta do crescimento da desigualdade de gênero: o surgimento de guerras e conquistas de longa distância, o desenvolvimento da agricultura de arado, e a atribuição das mulheres à esfera doméstica e, dos homens, à esfera pública durante o início da era industrial (Brym et al., 2008). O controle da propriedade, com a expansão do

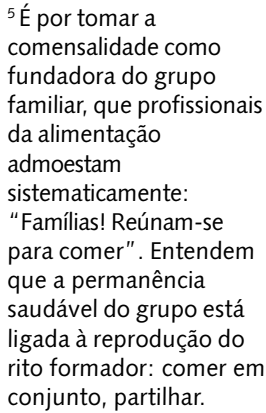


capitalismo comercial, sob domínio da família patriarcal, estabeleceu, definitivamente, a desigualdade de gênero (Passos, 2010).

Assim, o confinamento da mulher ao espaço privado representava uma garantia na preservação da posse dos bens paternos em torno da família patriarcal, e isso motivou o discurso de feministas, como Mary Wollstonecraft, em defesa dos direitos democráticos para as mulheres. No Brasil, a potiguar Nísia Floresta sustentou que a autoridade do homem usurpava a capacidade da mulher de conduzir sua vida por não conceder o seu acesso às ciências. Enfatizava, ainda, "a necessidade de dar acesso à instrução para as meninas" (Passos, 2010, p.8).

Até mesmo após a Revolução Francesa, a mulher era compreendida pela constituição imutável de sua natureza frágil, alienada e biologicamente concebida para cuidar. Havia a naturalização da ideia de que à mulher caberia a lida nos bastidores. A família monogâmica assegurava o poder incondicional ao homem. Essa relação pode ter inspirado Simone de Beauvoir a retratar a condição da mulher em sua obra intitulada O Segundo Sexo (1949). Assim, a monogamia apenas para o sexo feminino surgiu como uma forma de subordinação da mulher pelo homem, e sua relação impôs a primeira divisão do trabalho - a divisão sexual do trabalho entre o homem e a mulher (Passos, 2010).

Dessa forma, na Europa industrial, apenas o homem era útil. As mulheres, por sua natureza, eram mais cordatas e recatadas, devendo ser tuteladas e sujeitas a um domínio (Passos, 2010). A suposta necessidade de um domínio pode ter inspirado Pierre Bourdieu (1998) a publicar a obra A Dominação Masculina e estimulado Michelle Perrot a publicar Os Excluídos da História (1988), com reflexões sobre as relações hierárquicas de poder e limitação das escolhas individuais.

O pensamento que motivou o início do movimento feminista convergia para a busca da igualdade entre os sexos e compreendia, naquele contexto, a igualdade pelo caminho da educação intelectual e do direito ao voto. Tanto a morte de Olímpia de Gouges e as experiências de vida de Mary Wollstonecraft, quanto de Harriet Taylor e de Nísia Floresta influenciaram a discussão efetiva, em suas obras, sobre o direito à educação por parte das mulheres.

A busca pela liberdade foi marco fundamental para restabelecer a igualdade entre os sexos, pois incrementou o discurso de outras mulheres, como Harriet Taylor, que influenciou o marido, John Stuart Mill, a publicar o ensaio Sobre a Liberdade, em 1850, e A Sujeição das Mulheres, em 1869, em defesa dos direitos políticos femininos, com ideias sobre dignidade, autonomia e cidadania, fomentando a luta pelo sufrágio feminino, que obteve seu primeiro sucesso em 1897, no Reino Unido.

Em oposição à sua invisibilidade no contexto público, a mulher detinha o controle do culinário, enquanto espaço social, apenas na esfera privada. À lida nos bastidores, a mulher agregou gradualmente sua participação na vida pública. De início, tal participação ainda era arraigada ao espaço doméstico. Assim, sua condição de promotora da partilha e da comensalidade foi crescente até o surgimento do fast food, quando entra em declínio pela consequente individualização do comer fora de casa.

Ainda cabe a ela ordenar os horários das refeições, estabelecer cardápio,

${ }^{6}$ Não se resumem a essas as tarefas das mulheres em âmbito doméstico. Todavia, neste trabalho, só abordaremos as relacionadas com a

cozinha, desde o preparo até a distribuição. reservar os ingredientes, providenciar os equipamentos adequados para a produção da refeição e utensílios suficientes para o serviço. A comida deve estar pronta em tempo! Lembre-se de que o caçula sai da escola às onze, e o mais velho só chega do trabalho às 13 hs. Muito trabalho'. 
A comida é responsabilidade da mulher, muitas vezes uma das principais fontes do seu poder no lar. As mulheres recolhem a comida, fazem compras, escolhem o que deve ser comido e cozinham. Durante muito tempo, antropólogos sociais chamaram as mulheres de "porteiras" dos abastecimentos domésticos de comida. (Visser, 1998, p.279)

Tão forte tornou-se a correlação entre mulher, mãe e cuidado, que, mesmo no imaginário, tais conceitos são indissociáveis da realidade (Silva, 1998); são às figuras revestidas de formas de mulher que a humanidade roga por cuidado: Natureza, Mãe Terra, Pachamama, Gaia, Virgem Maria, lemanjá. Símbolos de proteção e heroínas pela resistência. No âmbito doméstico, a mãe é essa figura central de cuidado. Na ausência dela, quem cuida, prepara a comida, reúne a família para comer, são também mulheres, nos casos em que elas estão ali. Salvo raras exceções, homens não assumem esse papel quando elas estão ali.

Em famílias nas quais a mãe faleceu no contexto de HIV/Aids, o papel de cuidar da casa e dos filhos menores cabe às meninas-jovens-mulheres órfãs ${ }^{7}$. E, pensando na integralidade da palavra cuidado, na qual se circunscreve o bem-estar da família que roga por tarefas de cunho prático - leia-se lavar, cozinhar, passar -, essas meninas assumem, dentre outras tarefas, o monopólio da cozinha.

Veem-se fadadas a assumir um papel alheio ou o entendem como seu? O que relatam sobre isso? Poderia ser diferente? O que pensam, os irmãos, desse trabalho desenvolvido pelas irmãs cuidadoras? Essas são as impressões que buscamos nos discursos de 14 jovens, do sexo masculino e feminino, órfãos no contexto de HIV/Aids.

\section{Métodos}

Esta proposta de trabalho clama por olhar crítico e interrogativo, e busca a compreensão de fenômenos. Assim, a construção da metodologia se deu a partir da ideia de estratégia de Edgar Morin, para quem, diferentemente do programa, as finalidades são determinadas, e não as operações (Morin, 1999). Caberá ao artesão intelectuala organização destes dados (Mills, 2009).

$\mathrm{O}$ artesanato intelectual (re)liga objetos e conceitos, fornecendo material para um olhar complexo: aquele que procura "sempre as relações e inter-retro-reações entre cada fenômeno e seu contexto" (Morin, 1999, p.24). O pensamento unificador deve ser uma necessidade em projetos de caráter multiforme, nos quais componentes biológicos, psicoafetivos, sociais, culturais e ambientais coabitam. Foi esse pensamento que nos guiou nos momentos de pesquisa, escuta, análise, discussões.

A construção meninas-jovens-mulheres leva em conta a precocidade com que essas meninas adentram no mundo adulto. Será, dessa forma, utilizada neste trabalho para caracterizar os sujeitos da pesquisa, do sexo feminino, soropositivos ou não, que, em situação de orfandade, encontram-se responsáveis pelos cuidados da família. Dentre outras tarefas, essas "pequenas" possibilitam os momentos de comensalidade da família. São mulheres de casa, ainda que tenham sonhos de menina e sejam, fisicamente, jovens. A construção da palavra, formada por três menores, encadeadas por hífen, denota a situação híbrida dessas pessoas, num ciclo de vida que se torna indefinível, embora cronologicamente possamos afirmar que todos sejam jovens de até 21 anos. Inclusive os meninos, sobre os quais podemos dizer que forneceram discursos inalienáveis para a construção
${ }^{7}$ Quando não há filhas do sexo feminino, a tarefa de cuidar, muitas vezes, transfere-se para avós ou tias. Sempre mulheres. 
dessas impressões sobre o universo das mulheres e suas relações com o cuidado, a casa, a comensalidade.

Os sujeitos foram selecionados a partir de contato com os Serviços de Assistência Especializada (SAEs) em DST/Aids do município de São Paulo, localizados na zona oeste, leste e norte da cidade. Os SAEs facilitaram o contato com escolas, creches e Organizações não Governamentais (ONGs), que auxiliaram na seleção de jovens órfãos em função do adoecimento e morte das mães ou pais pela aids. Contatado o primeiro jovem, foi aplicado o princípio de indicações livre: este indicou outro passível de enquadramento na pesquisa, e assim por diante. Quatorze jovens órfãos, de ambos os sexos, entre 15 e 21 anos, forneceram entrevistas semiestruturadas. O Quadro 1 faz uma breve caracterização dos depoentes em termos de sexo, idade, sorologia para o HIV/Aids e o tipo de orfandade decorrente da morte materna, paterna ou de ambos:

Quadro 1. Perfil dos jovens entrevistados em São Paulo/SP, 2007

\begin{tabular}{|c|c|c|c|c|}
\hline Nome fictício & Gênero & Idade & Sorologia & Tipo de orfandade \\
\hline Antonieta & F & 15 & positiva & Materna \\
\hline Benjamin & M & 16 & positiva & Dupla \\
\hline Celina & F & 16 & negativa & Materna \\
\hline Elis & F & 16 & negativa & Dupla \\
\hline Fátima & F & 17 & negativa & Materna \\
\hline Gabriel & M & 18 & negativa & Dupla \\
\hline Humberto & M & 19 & positiva & Dupla \\
\hline Isabel & F & 19 & positiva & Dupla \\
\hline Joana & F & 19 & negativa & Dupla \\
\hline Letícia & F & 20 & negativa & Dupla \\
\hline Marina & F & 21 & negativa & Daterna \\
\hline Nicolau & M & 21 & negativa & Paterna \\
\hline Olga & F & 21 & negativa & Materna \\
\hline Penélope & F & 16 & negativa & \\
\hline
\end{tabular}

Em relação ao perfil do grupo, a maioria referiu ter cor da pele parda ou morena clara. Elas haviam parado de estudar, imediatamente ou um ano após a conclusão do Ensino Fundamental. Era comum o desejo de construir nova família pelo casamento. Algumas jovens estavam casadas e encontravam-se grávidas no momento da entrevista. Em geral, viviam em residências conjugadas de um único cômodo ou, então, moravam junto com os avós ou tios, dividindo as pequenas instalações e as despesas. $\mathrm{O}$ quintal, como um núcleo comum às casas adjacentes, complementava o cenário de acesso e convivialidade nos bairros da periferia.

Durante as entrevistas, os sujeitos foram estimulados a falar sobre seu cotidiano. Utilizamos, para tal fim, um pequeno roteiro-guia que incluía perguntas sobre: o que os meninos pensavam do trabalho desenvolvido pelas irmãs em âmbito doméstico; se as meninas viam desvantagens em relação aos meninos ao se perceberem como responsáveis por essas tarefas; com que futuro sonhavam as jovens.

O presente estudo integra a pesquisa Comensalidade de jovens órfãos por Aids, desenvolvida junto à Faculdade de Saúde Pública da Universidade de São Paulo. Foi realizado de acordo com as Normas e Diretrizes Éticas da Resolução 196/96 do Ministério da Saúde, e aprovado pelo Comitê de Ética em Pesquisa da Faculdade de Saúde Pública em 28 de maio de 2007. Todos os participantes assinaram o Termo de Consentimento Livre e Esclarecido. Para os sujeitos de 15 a 18 anos, que tivessem sido autorizados a participar da pesquisa por seus pais ou responsáveis, criou-se o Termo de Assentimento. 
As entrevistas foram realizadas em uma sala reservada para este fim, no prédio da Faculdade de Saúde Pública da Universidade de São Paulo. Em algumas situações, todavia, os sujeitos solicitaram que as entrevistas fossem realizadas em suas casas. Nesses casos, atenção especial foi dirigida à questão da privacidade do sujeito. Locais reservados foram eleitos.

As entrevistas foram gravadas em mídia analógica. Uma conversão foi operada para mídia digital visando a uma melhoria na qualidade do som (diminuição de ruídos externos e nitidez da voz dos narradores). Pessoal qualificado foi contratado para transcrever as narrativas. O corpus, já transcrito, foi revisado pelos pesquisadores.

Para a análise, as narrativas foram percorridas em busca de discursos que versassem sobre as questões que levantamos inicialmente ao elaborarmos o roteiro. Os fragmentos encontrados foram ordenados por bricolagem e as discussões são apresentadas adiante.

\section{Resultados e discussão}

Cuidar do outro, mais que gentileza, ser colo que acolhe, afetar-se e sentir-se afetado, envolve realizar tarefas cotidianas tidas como "coisa de mulher". Essa ideia é plantada na mente de algumas mulheres, que "passam a fazer assim porque sempre se fez assim", Gabriela, Cravo e Canela, de Jorge Amado (1958), é um exemplo literário dessa naturalidade cristalizada cotidianamente: "Eu nasci assim, eu cresci assim, e sou mesmo assim, vou ser sempre assim...". Observa-se aqui a expressão-chave de discursos conformistas, mantenedores da ordem e perpetuadores de modos cômodos de ser e de viver habitualmente. Para Pierre Bourdieu (1998), são essas estruturas invariantes, criadoras do habitus, que perpetuam a dominação masculina.

Assim, este pequeno recorte de trabalho deseja demonstrar que não há "uma natureza feminina imanente e estável que destinaria definitivamente as mulheres aos trabalhos domésticos" (Giard, 2008, p.211). Não se trata disso. Antes, será feito o esforço para se compreender pelo menos uma das razões que relegam à mulher a tarefa do cuidado da família, do monopólio da cozinha, e, entrecruzando esses dois papéis, da direção dos ritos de comensalidade e, ainda, sobre a divisão de tarefas domésticas.

No interior da dicotomia público/doméstico, permanece uma ambiguidade, resultando diretamente das práticas e teorias patriarcais do passado, que têm sérias consequências práticas - especialmente para as mulheres. A divisão do trabalho entre os sexos tem sido fundamental para essa dicotomia desde seus princípios teóricos. Os homens são vistos como, sobretudo, ligados às ocupações da esfera da vida econômica e política, e responsáveis por elas, enquanto as mulheres seriam responsáveis pelas ocupações da esfera privada, da domesticidade e reprodução (Okin, 2008).

Por isso, as mulheres são vistas como ligadas ao mundo da casa, ao doméstico e ao cuidado dos filhos. A capacidade corporal feminina relacionada à reprodução da espécie humana delimita o espaço da mulher na vida em sociedade; seu papel de 'cuidadora' confere-lhe uma posição hierárquica inferior em relação aos homens publicamente ativos e provedores. (Sayão, 2003, p.123)

À luz de representações comuns, seria possível dizer que os homens estariam na esfera da vida produtiva, enquanto as mulheres na esfera da vida reprodutiva, como distingue Izquierdo (1994). Assim, se reproduz e se reconfigura permanentemente a "velha" divisão social/sexual do trabalho (Sayão, 2003), embora historicamente essa divisão nem sempre tenha sido tão desigual (Brym et al., 2008). É fato que o papel da mulher como administradora da casa, ocupada das coisas do lar, é bastante antigo. Já na pré-história a mulher tinha múltiplas funções, e, para assegurar o crescimento do grupo, era "criadora, fixadora e transmissora de hábitos culturais", o que contribuiu na passagem à Revolução Neolítica, pois "domesticavam animais (pecuária), fabricavam cerâmica, tecidos e exerciam medicina caseira" (Sá, 1996, p.160). Sua atuação como dona de casa foi fixando-se com o passar da história, a tal ponto que Markham, escritor inglês de livros de cozinha, em 1615, na sua obra The English Hus-wife, retrata sobre: 
Todas las cualidades interiores y exteriores que deberían encontrarse en una mujer perfecta: su competência en medicina, cocina, pastelería, destilación, perfumes, lana, cáñamo, lino, lechería, cervecería, panadería y otras cosas referidas a la administración del hogar. (Samper, 1997, p.129)

Dessa maneira, "trabalho doméstico" e "ofício de mulher" foram expressões que caminharam juntas durante anos e anos. São representações de mulheres as obras de belas artes que retratam a cozinha, bem como a preparação de alimentos. Os clássicos: $A$ velha fritando ovos (1618), do espanhol Diego Velázquez, A Polenta (1735-1740), do italiano Pietro Longhi, A Leiteira (1658-1660), do holandês Johannes Vermeer, são excelentes exemplos.

Quando começa essa formação da mulher? "Não se nasce mulher. Torna-se mulher", afirma Beauvoir (1980, p.9). Então, quando a menina-jovem torna-se mulher? Cora Coralina mostra que, já na infância, é comum que a menina ajude ativamente nas tarefas do lar. No conto As cocadas, em estilo autobiográfico, ela conta como ajudava no preparo de doces que, já muito cedo, eram o sustento da família:

Eu devia ter nesse tempo dez anos. Era menina prestimosa e trabalhadeira à moda do tempo. Tinha ajudado a fazer aquela cocada. Tinha areado o tacho de cobre e ralado o coco.

Acompanhei rente à fornalha todo o serviço, desde a escumação da calda até a apuração do ponto. Vi quando foi batida e estendida na tábua, vi quando foi cortada em losangos. Saiu uma cocada morena, de ponto brando atravessada de paus de canela cheirosa. O coco era gordo, carnudo e leitoso, o doce ficou excelente. (Coralina, 2001, p.3)

É esta máscara da evidência primeira, construída milenarmente, uma das razões da marca do cuidado atribuído às mulheres. A grande pergunta, todavia, seria: por que milenarmente essas foram as tarefas das quais se ocuparam as mulheres? Uma hipótese seria o fato de serem as mulheres as geradoras de vida, o que lhes dotaria de grande poder, principalmente nas sociedades fundadas no parentesco. Uma outra hipótese é levantada por Perrot (1988), ao afirmar que, mediante a dominação masculina, as mulheres desenvolvem estratégias ligadas à vida cotidiana, as quais lhes conferem poderes.

Em razão desses supostos poderes, surgiram várias instituições para controlar o corpo e as práticas femininas. A culpa religiosa doutrinou a liberdade feminina em relação ao próprio corpo, e a medicina fez do corpo feminino uma das maiores mercadorias. A medicalização da dieta também desmereceu o saber da elaboração de pratos tradicionais. Portanto, a abordagem do cuidado no cotidiano feminino requer, de acordo com Bourdieu (1998, p.21), "a percepção de que ser homem ou mulher é parte e parcela do objeto que tentamos compreender."

Então, o masculino torna-se sinônimo de rua, enquanto que a cozinha, a casa tornam-se sinônimos de feminino. E, por conta dessa divisão, recebem atribuições de valores. Tarefas consideradas menores, porque exercidas gratuitamente, couberam às mulheres. Certo é que a sociedade, hoje, assiste a mudanças nessa configuração, mas o senso comum nos mostra que a tarefa cotidiana de cozinhar é apreendida e compreendida como de mulheres. A mudança ocorre em direção ao acúmulo de papéis; as mulheres se portam como "deusas" de mil braços, virando-se para lá e para cá, levando mil tarefas ao mesmo tempo (Medeiros, 2010).

"A mulher serve e o homem come", diria Cascudo (2004, p.54). "Introduce, maneja e integra nuevos elementos, adaptándose a nuevas situaciones, pero sin perder casi nunca de vista el espíritu más cercano a lo 'tradicional', en el que la centralidad es para la tierra y la casa" (Ramírez, 2007, p.7). São "o centro da célula familiar" (Ceccim, Palombini, 2009, p.168). Cuidam em todos os gestos, administram cada detalhe, cozinham e servem.

O mais triste é que esse trabalho não conduz a uma criação duradoura. A mulher é tentada tanto mais quanto mais cuidado nela pôs - a considerar sua obra como um fim em si. Contemplando o bolo que ela tira do forno, ela suspira: é realmente uma pena comê-lo! [...] É preciso, portanto, que o produto do trabalho doméstico se consuma; uma renúncia 
constante é exigida da mulher, cujas operações só terminam com a destruiç̧ão. (Beauvoir, 1980, p.207)

Entre os órfãos no contexto de HIV/Aids que entrevistamos, não se identifica entendimento contrário a esse. Principalmente entre os meninos, percebe-se um discurso que entende que ser mulher institui uma predisposição para a lida doméstica: "Mulher é melhor com o serviço da casa. Já sabe fazer tudo! Limpar a casa inteira. Se for mulher, já sabe fazer o serviço, já é diferente!", diz Nicolau. Humberto pensa da mesma maneira: "Mulher é mais organizada, mais decidida. Mulher é mais caseira, mais espírito família".

É como se as tarefas desenvolvidas fossem fruto de um fluxo natural das coisas, que constroem uma situação de estaticidade: "mulher é da casa, homem é da rua," deduz Benjamim; há as tarefas de homens e as de mulheres. Benjamim relata como se dá a divisão de tarefas na sua casa, na ocasião de uma festa: "Os meninos colocam a lâmpada e saem de perto pra não atrapalhar. As mulheres fazem almoço [...] Os homens vão zoar. É, a gente fica só: 'Ô, cuidado pra não queimar, tal. Vai lá, coloca o fogo'."

A naturalização na divisão de tarefas ligadas ao cotidiano feminino é percebida pela resistência masculina em cooperar. Essa percepção chega a tal ponto que mesmo uma atividade como comprar pão é tida como coisa de mulher, não havendo acordo para que um homem na casa possa comprá-lo. Tarefas simples como a compra de alimentos não são bem recebidas para execução por meninos. Gabriel relata: "Teve uma vez que meu tio pediu pra comprar pão e eu não queria". A recusa em desempenhar tarefas domésticas resultou em episódios de violência. Isso foi demonstrado em declaração de Gabriel envolvendo o tio: "Ele me deu um monte de paulada nos braços, eu fiquei todo roxo, só porque eu não quis comprar pão". Tarefas domésticas, mesmo executadas sob violenta imposição, não são facilmente incorporadas ao cotidiano dos meninos: "Outra vez, pelo mesmo motivo, eu apanhei de novo, porque não quis comprar pão de novo", recorda Gabriel.

Ao contrário do que entendem seus irmãos, muitas dessas meninas-jovens-mulheres, naturalmente, não se sentem como nascidas para isso. Os sentimentos perpassam a sensação de despreparo. É como se fosse delegado a elas um papel que ainda é compreendido como o papel da mãe. Penélope, que parou de estudar para cuidar da família, após a morte da mãe, relata: “Eu lembro dela porque só ela sabia fazer aquela lasanha, hoje ninguém, eu faço, mas nunca é o gosto, nunca fica a mesma coisa, sabe?" Penélope recorda a lasanha preparada pela mãe falecida e revela que não consegue repetir a experiência materna porque, segundo ela, "O gosto nunca é o mesmo, para mim sempre a lasanha tem que lembrar dela." A memória materna se faz presente na fala de Penélope, demonstra a tentativa de repetição dos mesmos procedimentos que a mãe adotava: "É uma coisa que quando eu faço tem que tentar fazer do jeito que ela fazia". Ela admite que, mesmo na execução de outras receitas, o sucesso materno parece insubstituível: "Ela fazia também o sagu. Eu tentei fazer uma vez, não deu certo, ficou tudo grudado. Várias coisas, entendeu?". Penélope recorda do contexto doméstico, do olhar, da presença materna, do aprendizado pela observação: "Que eu via ela fazendo e fazia então. Sempre ela fazia, eu via, ela olhava pra mim sempre. Eu ali, aprendendo". Penélope atribui a dificuldade de conseguir executar alguns pratos a aspectos afetivos, que vão muito além da saudade, e da memória do gosto e da perfeição culinária que remete à mãe.

Entendendo que o monopólio da cozinha não é algo inato a elas, pelo simples fato de serem mulheres, as meninas-jovens-mulheres demonstram o desejo de mudança na divisão de tarefas. A insatisfação quanto às partes que cabem a elas na pluralidade do espaço da casa não raras vezes emerge no discurso no momento em que elas passam a enumerar as vantagens de ser homem: "Para o homem (a realização de planos) talvez seja mais fácil. Homem consegue arrumar trabalho mais facilmente," infere Olga. Enquanto Celina aponta como vantagem o fato de que "menino pode estar em qualquer lugar". Ou ainda quando elas passam diretamente a questionar as inumeráveis tarefas que cabem a elas por serem mulheres, como é o caso de Joana: "Por que queriam exigir só de mim? Eu tinha que cuidar da minha avó, tinha que cuidar da casa". Elis refere que sempre ouvia da tia frases tais como: "Você é a menina da casa! Você tem que dar respeito! "Essas meninas-jovens-mulheres assumem o cuidado desde cedo e revelam desvantagens de gênero na lida doméstica. Elis, com apenas 16 anos, compara: 
${ }^{8} \mathrm{Na}$ abordagem da insatisfação e das possibilidades de mudanças, apenas analisaremos o discurso das meninas, já que o objetivo do estudo é mostrar como elas entendem a obrigação do cuidar da família, através das tarefas que transitam na cozinha.
"Você vê seus irmãos tudo feliz, curtindo. Você ali tendo que trabalhar o dia-a-dia para ter o pão de cada dia". Assim, o cuidado parece reproduzir-se pela hierarquia feminina como um elo de resistência e responsabilidade, precocemente reverenciado nas práticas femininas: "Com dez anos de idade eu já fazia tudo pra minha mãe", conclui Fátima, de 17 anos.

Indo em caminho divergente às demandas impostas pelo cotidiano, as meninas passam a cultivar no sonho a vida que gostariam de ter no futuro. "Transforma a prosa do cotidiano em poesia da vida" (Morin, 2007, p.24). Esses discursos, quando comparados com a realidade cotidiana em que vivem, mostram quão distantes de uma situação desejável elas ${ }^{8}$ vivem. Nos sonhos que relatam, possuem suas casas próprias, têm filhos, cozinham, comem com a família; todavia, têm suas profissões num ambiente externo ao doméstico. Estudar é um dos sonhos mais mencionados. Não por acaso, serão futuras enfermeiras, como relata Isabel. Antonieta sonha em "terminar a escola e ser empresária. Administrar empresas". Ter a possibilidade de "sair assim para uma praça, ir lanchar numa lanchonete ou então ir para um clube, escolher assim todo final de semana algum lugar para ir", acrescenta Marina. Ainda que preparando o alimento, ter a possibilidade de nem arrumar a cozinha, quando essa for a vontade. Querem liberdade para escolher.

Ainda que esteja complexamente relacionada com pertencimentos identitários, crenças, reciprocidade e cuidado, ou seja, mostre-se intrínseca à vida humana, a comensalidade custa algo. No "invisível do cotidiano", tarefas são executadas maquinalmente (Giard, 2008, p.234). Arrumar para, em seguida, desarrumar, limpar para sujar, cozinhar para devorar: o cuidado da família por fornecer alimentos que serão consumidos em âmbito doméstico é tarefa que cabe às mulheres na divisão de tarefas corrente, divisão que se reproduz neste microcosmo da orfandade no contexto de HIV/Aids. A elas, essas mulheres, é cobrado o preço.

[...] Porque a pesar que son los indivíduos los que actúan, sus prácticas están fuertemente condicionadas por las decisiones del colectivo, así se explica que haya estrategias familiares que 'condenan' a alguno de sus miembros - el caso de la madre sacrificada. (Aguirre, 2004, p.11)

Cuidar, por e pela comensalidade, custa abrir mão de possibilidades outras. "Assumem responsabilidades que vão muito além das suas capacidades como crianças" para exercerem o papel de cuidadoras (Kelly, 2000, p.41). O que incomoda essas meninas não é o fato de terem de realizar tarefas desse tipo, mas o fato de essas tarefas serem tomadas como inerentemente delas, como uma espécie de herança da habilidade para cuidar. Cuidar, no sentido mais prático no contexto da Aids, que envolve o remediar, alimentar e acolher entre os dois mundos: o que se despede da vida, que se refere ao processo de adoecimento das mães: "Come, mãe. E ela: não, eu não quero comer" (Elis); completa Fátima: "e eu com dez, 12 anos, com 11 anos de idade, cuidava da minha mãe doente na cama, cuidava da minha irmã também"; e o que as transforma em sujeitos responsáveis pelo cuidado das vidas que seguem, seus irmãos. Celina diz: "No hospital, eu fico das seis da manhã até duas horas da tarde. Uma vez por mês. Agora ela está melhor porque ela está tomando o remédio certinho. Eu pego no pé dela". A jovem de 16 anos é responsável pelo cuidado da irmã menor, com nove anos de idade e soropositiva.

Os pais representam proteção e amparo, além de indicarem o caminho. Sem sua presença, as jovens órfãs são impelidas numa independência forçada e têm de 
descobrir sua identidade mais rapidamente ainda, pois, se não o fizerem, os outros simplesmente decidirão por elas: “'Perdeu o pai e a mãe, já era! Esse vai ser bandido', minha tia falava: 'Imagine essa menina sem o pai, sem a mãe, o que vai ser dela? Vai ser uma ladrona! Vai ser uma vagabunda'" , ouviu Elis.

Elas são apresentadas às misérias da vida cedo demais, e têm de superar isso mais cedo ainda, antes que se percam no caminho. São obrigadas a serem independentes pela necessidade, pois não há mais um pai ou uma mãe para adiar esse aprendizado. "Então ser órfão não é bom, porque os medos são maiores, as inseguranças maiores ainda, porque, quando temos os pais, tem a orientação, tem os exemplos. Outras pessoas querem o nosso bem, mas não tanto quanto os pais. Então ser órfão é dificil", concluiu Letícia.

$\mathrm{Na}$ conformação da orfandade, o cuidado permanece como um legado no qual a execução de tarefas maternas tende a recair como obrigação para as filhas, que tenderão a desempenhar, com o próprio corpo, existência, presença, permanência, o sentido de família e de lar para os irmãos menores.

O "outro" que assim se apresenta é um outro englobante, o ambiente (social e físico) ou um objeto que desempenha as funções de acolher, hospedar, agasalhar, alimentar: no limite e no início da vida, ele pode nem ser reconhecido como um outro diferente de mim, mas ao longo de toda a nossa existência só vivemos bem quando podemos contar com algo ou alguém capaz de exercer estas tarefas transubjetivas, mesmo que já percebamos que há uma diferença e uma separação entre nós e este outro. (Figueiredo, 2009, p.125, grifo nosso)

O adentramento destas meninas-jovens para a lida com o "monopólio da cozinha" assemelha-se, simbolicamente, ao pensamento indígena documentado por Lévi-Strauss em O cru e o cozido:

Cozinham-se indivíduos intensamente engajados num processo biológico - ${ }^{-}$...] menina púbere. A conjunção de um membro do grupo social com a natureza deve ser mediatizada pela intervenção do fogo da cozinha, normalmente encarregado de mediatizar a conjunção do produto cru com o consumidor humano, e por cuja operação um ser natural é, ao mesmo tempo, cozido e socializado. (Lévi-Strauss, 2004, p.380)

Similar ao pensamento indígena, a lida com as operações culinárias é vista como "atividades mediadoras entre o céu e a terra, a vida e a morte, a natureza e a sociedade" (Lévi-Strauss, 2004, p.89). Assim, o adentramento prematuro da menina mais velha à lida com "o monopólio culinário" estabelece a passagem do seu estado de menina, relativo ao estado cru do universo infantil, e conduz ao estado de menina-jovem-mulher, portanto, apta para cuidar. A comensalidade seria a manifestação prática do cuidado, a medida de amolecimento do cotidiano bruto da vida que responsabiliza, antes da hora, pela fome do outro. Então, a comida precisa ser cozida, diluída, repartida, para converter-se em companhia ${ }^{9}$, como legado que bastasse por si só em suas trajetórias rumo ao universo adulto.

A irmã mais velha, em particular, é assim amiúde associada às tarefas maternas. [...] Ela é então precocemente integrada no universo da seriedade. [...] Ela experimenta o orgulho de ser eficiente como um adulto e regozija-se de ser solidária com as pessoas "grandes." [...]
${ }^{9}$ Companhia deriva da palavra latina companion, que significa literalmente: "uma pessoa com quem partilhamos o pão" (Visser, 1998, p.3) 
Permite-se, pede-se mesmo à irmã, que varra, tire o pó, limpe os legumes [...] tome conta da sopa. (Beauvoir, 1980, p.27)
Esse evento da brusca transição de universos, do infantil ao adulto, ter de cuidar sem ter cuidador, foi previsto de ocorrer no Brasil, há mais de uma década. Cássia Buchalla previa que a elevada mortalidade de adultos jovens faria aumentar o número de órfãos:

Em algumas áreas, a morte dos pais significa que as crianças serão responsáveis por seus irmãos menores, tendo que desempenhar, precocemente, o papel de chefes de família, abandonar os estudos e assumir responsabilidades para as quais não estão preparadas. (Buchalla, 1995, p.331)

Essa circunstância, onde os horizontes e projetos de pessoas jovens são preteridos em razão do cuidado familiar como legado, é chamada por Ayres (2006) de restrição de horizontes ${ }^{10}$.

O número de meninas trabalhadoras é menor do que o de meninos. Este fato não significa que elas trabalhem menos. A dedicação exclusiva aos afazeres domésticos, sem escola, atinge quase dois milhões de crianças e adolescentes entre dez e 17 anos. Temos um enorme contingente de crianças e adolescentes, principalmente meninas, que cuida da casa e dos irmãos. O trabalho dessas meninas é exaustivo e fundamental para a manutenção das famílias, já que representa a única opção de cuidado. [...] É um tipo de atividade que exige dedicação integral, o que impede a ida à escola. (Rizzini, 1999, p.382)

Uma das perdas mais impactantes sentida pelas jovens e atribuída à falta dos pais consistia na dificuldade para estudar. A orfandade sempre esteve vinculada à pobreza e a situações de exploração social, além da violação de direitos humanos (Huberman, 1959). No caso dessas jovens, a morte dos pais e a herança do cuidado criam obstáculos à educação, impedindo-as de usufruírem das conquistas públicas alcançadas por outras mulheres no passado.

No presente ensaio, as meninas-mulheres-jovens referem ter abandonado os estudos com o fim de responder às demandas que exigiam delas seu "braço de mulher". O problema não está com as responsabilidades que transacionam cuidado e comensalidade, é, na verdade, o como elas se apresentam na vida delas.

[...] Escolhendo cuidar dos assuntos do lar e da educação da família, como primeira exigência de seu empenho durante muitos anos de sua vida [...] renuncia não a todos os objetivos e ocupações, mas a todos os que não são consistentes com as necessidades de cuidar do lar. (Mill, 2006, p.73)

Enquanto desempenham o cuidado, sonham com uma vida polifônica, de vozes que se encontram em seus pertencimentos múltiplos, onde cada um e todos os campos de suas vidas poderiam se unir para dar-lhes uma vida mais flexível e realizada. Hoje, têm o direito de estudar, mas elas não estão disponíveis para usufruí-lo. 
A vida das mulheres que trabalham fora é mais polifônica, porque não perdem o contato com a família, com os amigos, conjugando experiências diversas, em diferentes níveis, sem sacrificar as relações afetivas em prol da carreira. (De Masi, 2000, p. 204 apud Di Ciommo, 2003, p.439)

Ainda que a ingenuidade da visão de que uma experiência múltipla não preterisse nenhuma esfera da vida, é essa a vida que as jovens relatam em sonho. Querem ser mães, donas de casa, ter independência, seu próprio dinheiro, curtir com amigos, estudar, ter uma carreira, comprar um carro. É como se, usando a voz de Fernando Pessoa, dissessem: "À parte isso", à parte de toda essa realidade, desse cotidiano que me sufoca, que me impede de realizar agora meus desejos e vontades, "tenho em mim todos os sonhos do mundo" (Pessoa, 1997, p.184).

\section{Considerações finais}

Ouvir constitui um exercício primordial do fazer ciência. Este trabalho nasceu como fruto dessa escuta. Prestar atenção, observar, ouvir, além de escutar. Problemas novos criam a necessidade de se pensarem soluções novas.

Há algumas poucas décadas, a Aids era uma enfermidade que simplesmente não existia. Aos poucos, foi sendo concebida como algo distante, algo que poderia ocorrer somente no continente africano. Hoje, já uma pandemia global, gera novos problemas para a sociedade. As crianças órfãs no contexto de HIV/Aids, por exemplo, "têm necessidades econômicas e psicológicas diferentes das outras crianças da escola, necessidades essas que a escola deve, necessariamente, procurar responder" (Kelly, 2000, p.41). E não apenas a escola. Mais poderia ser feito.

A compreensão da beleza desse lugar que é a cozinha, a "metáfora da vida", poderia trazê-las para perto (Medeiros, 2010). As meninas-jovens-mulheres parecem demandar cuidados que se direcionem de modo a que elas não abandonem os estudos. Os meninos poderiam ser levados a perceber que poderiam auxiliar suas irmãs nas tarefas. Quem sabe um programa de educação alimentar, para além da nutrição do corpo, poderia ajudar os adolescentes a ressignificarem sua relação com os alimentos, com a cozinha e a comensalidade.

Enquanto seres humanos em busca de uma sociedade diferente, nos cabe dialogar no sentido de compreender que, embora homens e mulheres sejam diferentes, "se encontram no mesmo chão comum da humanidade" (Boff, 2008, p.139), humanidade que se nutre, que come junto e que, através da comensalidade, transforma o comer em comunhão. Animus e anima, duas faces de um ser humano complexo.

\section{Colaboradores}

Os autores trabalharam juntos em todas as etapas de produção do manuscrito.

\section{Referências}

AGUIRRE, P. Seguridad alimentaria: una visión desde la antropología alimentaria. Desarrollo integral en la infancia: el futuro comprometido. Córdoba: Fundación CLACYD, 2004.

AMADO, J. Gabriela, cravo e canela: crônica de uma cidade do interior. São Paulo: Record, 1998.

AYRES, J.R.C.M. Cuidado e reconstrução das práticas de saúde. Interface - Comunic., Saude, Educ., v.8, n.14, p.73-92, 2004. 
AYRES, J.R.C.M. et al. Vulnerability, human rights, and comprehensive health care needs of young people living with HIV/Aids. Am. J. Public Health, v.96, n.6, p.1001-6, 2006.

BEAUVOIR, S. O segundo sexo. Rio de Janeiro: Nova Fronteira, 1980.

BETTO, F. Meu lado mulher. Caros Amigos, São Paulo, n.168, mar.2011.

BOFF, L. Saber cuidar: ética do humano, compaixão pela Terra. 11.ed. Petrópolis: Vozes, 2008.

BOURDIEU, P. La domination masculine. Paris: Seuil, 1998.

BRYM, R.J. et al. Sociologia: sua bússola para um novo mundo. São Paulo: Cengage Learning, 2008.

BUCHALLA, C.M. Aids: o surgimento e a evolução da doença. In: MONTEIRO, C.A. (Org.). Velhos e novos males de saúde no Brasil: a evolução do país e de suas doenças. São Paulo: Hucitec, 1995. p.331-45.

CASCUDO, L.C. História da alimentação no Brasil. 3.ed. São Paulo: Global, 2004.

CECCIM, R.B.; PALOMBINI, A.L. Imagens da infância, devir-criança e uma formulação à educação do cuidado. In: MAIA, M.S. (Org.). Por uma ética do cuidado. Rio de Janeiro: Garamond, 2009. p.155-84.

CORALINA, C. As cocadas. São Paulo: Global, 2007.

DI CIOMMO, R.C. Relações de gênero, meio ambiente e a teoria da complexidade. Rev. Estud. Fem., v.11, n.2, p.423-44, 2003.

FIGUEIREDO, L.C. As diversas faces do cuidar: considerações sobre a clínica e a cultura. In: MAIA, M.S. (Org.). Por uma ética do cuidado. Rio de Janeiro: Garamond, 2009. p.121-40.

GIARD, L. Cozinhar. In: CERTEAU, M.; GIARD, L.; MAYOL, P. (Orgs.). A invenção do cotidiano 2: morar, cozinhar. 8.ed. Petrópolis: Vozes, 2008. p.209-332.

HUBERMAN, L. História da riqueza do homem. Rio de Janeiro: LTC, 1986.

IZQUIERDO, M.J. Uso y abuso del concepto de gênero. In: VILANOVA, M. (Org.). Pensar las diferencias. Barcelona: UB/Institut Català de la Dona, 1994. p.31-53.

KELLY, M.J. Planear para educação no contexto do HIV/Sida. Paris: Unesco/IIPE, 2000.

LÉVI-STRAUSS, C. O cru e o cozido. São Paulo: Cosac \& Naify, 2004.

MEDEIROS, M. Como você aprendeu a cozinhar? Reflexões sobre a transmissão intergeracional do conhecimento culinário entre mulheres. In: CONGRESSO INTERNACIONAL DE PESQUISA (AUTO)BIOGRÁFICA, 4., 2010, São Paulo. Anais... São Paulo, 2010. 1 cd-rom.

MILL, J.S. A sujeição das mulheres. São Paulo: Escala, 2006.

MILLS, W. Sobre o artesanato intelectual e outros ensaios. Rio de Janeiro: Jorge Zahar, 2009.

MOREIRA, S.A. Comensalidade de jovens órfãos pela Aids em São Paulo. Brasília. CNPq/COSAU, 2009.

MORIN, E. As duas globalizações: complexidade e comunicação. 3.ed. Porto Alegre: Sulina/EDIPUCRS, 2007.

Complexidade e transdisciplinaridade: a reforma da universidade e do ensino fundamental. Natal: EDUFRN, 1999.

OKIN, S.M. Gênero, o público e o privado. Rev. Estud. Fem., v.16, n.2, p.305-22, 2008. 
PASSOS, C.C. A primeira geração do feminismo: Um diálogo crítico com o pensamento liberal. In: FAZENDO GÊNERO, 9., 2010, UFSC. Anais... Santa Catarina, 2010.

Disponível em: <http://www.fazendogenero.ufsc.br/9/>. Acesso em: 22 jun. 2012.

PERROT, M. Os excluídos da história: operários, mulheres e prisioneiros. Rio de Janeiro: Paz e Terra, 1988.

PESSOA, F. O guardador de rebanhos e outros poemas. São Paulo: Cultrix, 1997.

RAMÍREZ, J.P. Hibridez y género: reflexiones sobre el Mediterráneo desde Andalucía oriental. Gazeta Antropol., n.23, p.1-19, 2007.

RIZZINI, I. Pequenos trabalhadores do Brasil. In: DEL PRIORE, M. História das crianças no Brasil. São Paulo: Contexto, 1999. p.376-406.

SÁ, C.A.M. O universo, a vida, a sociedade e a sexualidade humana. R.B.S.H. v.7, n.2, p.157-63,1996.

SAMPER, M.A.P. Los recetarios de mujeres y para mujeres. Sobre la conservación y transmisión de los saberes domésticos en la época moderna. Cuad. Hist. Mod., n.19, p.121-54, 1997.

SAYÃO, D.T. Corpo, poder e dominação: um diálogo com Michelle Perrot e Pierre Bourdieu. Perspectiva, v.21, n.1, p.121-49, 2003.

SILVA, J.M. Visões de uma certa Europa. Porto Alegre: EDIPUCRS, 1998.

VAN GENNEP, A. Os ritos de passagem. Petrópolis: Vozes, 1977.

VISSER, M. O ritual do jantar: as origens, evolução, excentricidades e significado das boas maneiras à mesa. Rio de Janeiro: Campus, 1998.

MOREIRA, S.A. et al. Comensalia y cuidado: chicas-jóvenes-mujeres huérfanas en el contexto del VIH/Sida. Interface - Comunic., Saude, Educ., v.16, n.42, p.651-64, jul./set. 2012.

Histórica y culturalmente, el "monopolio de la cocina" se atribuye a las mujeres, a las madres. Para cuidar de la familia eligen los alimentos, los compran, los cocinan y los sirven. Mantienen la comensalia. En el contexto del VIH/SIDA, cuando la madre muere, las hijas se hacen responsables de dichos cuidados. ¿Qué piensan las niñas del papel de cuidadoras? ¿Qué dicen sus hermanos al respecto? Realizamos entrevistas semiestructuradas con 14 jóvenes huérfanos. Los datos fueron analizados por la propuesta de Mills (2009). Las huérfanas no mostraron descontento por desarrollar nuevas tareas, pero lamentaron el hecho de que esas tareas les impiden de estudiar y vivir una vida más allá del hogar. Sus hermanos conciben la cocina como cosa de mujeres y casi nunca colaboran. Estas jóvenes necesitan de atención por su situación de vulnerabilidad. Las políticas de Salud Pública podrían reclamar macro-estructuras para cubrir esa demanda.

Palabras clave: Comensalia. Cuidado. Niños huérfanos. Síndrome de Imunodeficiência Adquirida. Jóvenes.

Recebido em 10/06/11. Aprovado em 12/06/12 